\title{
RECONSIDERACIÓN DE LA PROHIBICIÓN DE SUCEDER: EL CASO DEL TUTOR O CURADOR
}

\author{
A reconsideration of the prohibition to inherit: \\ the case of the guardian or the curator \\ SOFÍA DE SALAS MURILLO \\ Universidad de Zaragoza \\ sofiasal@unizar.es
}

Cómo citar/Citation

De Salas Murillo, S. (2019).

Reconsideración de la prohibición de suceder: el caso del tutor o curador.

Derecho Privado y Constitución, 35, 57-85.

doi: https://doi.org/10.18042/cepc/dpc.35.02

(Recepción: 12/12/2018; aceptación tras revisión: 21/10/2019; publicación: 29/11/2019)

\section{Resumen}

El artículo propone reconsiderar el mantenimiento de una de las tradicionales incapacidades para suceder de nuestro sistema jurídico: la del art. $753 \mathrm{CC}$ respecto al tutor o curador del testador. Y ello no solo desde la perspectiva tendente a reducir los límites de la libertad para testar en sí mismos, sino desde lo que supone para la persona con discapacidad, en relación con el libre desarrollo de su personalidad, en el ámbito de disposición mortis causa de sus bienes. La Convención de Nueva York no se pronuncia expresamente sobre ello, pero del espíritu de su art. 12 cabe extraer esta conclusión. Sin embargo, el Anteproyecto de Ley de reforma del Código civil mantiene esta incapacidad respecto a la figura del curador representativo. En el trabajo se plantean, partiendo de la propuesta de supresión de la misma, soluciones alternativas para conciliar los valores jurídicos que concurren en este caso.

\section{Palabras clave}

Libertad para testar; incapacidad para suceder; persona con discapacidad; tutor; curador representativo. 


\begin{abstract}
The paper proposes to reconsider the maintenance of one of the traditional incapacities to inherit of our legal system: that of art. $753 \mathrm{Cc}$ regarding the guardian or curator of the testator. And this not only from the perspective tending to reduce the limits to freedom of disposition by will, but from what it means for the person with disabilities, in relation to the free development of their personality, in the context of disposition mortis causa of their goods. The New York Convention does not expressly pronounce on it, even though the spirit of its art. 12 this conclusion can be drawn. However, the Draft Law for the reform of the Civil Code maintains this incapacity regarding the representative curator. This paper proposes, based on the proposal to suppress it, alternative solutions to reconcile the legal values that concur in this issue.
\end{abstract}

\title{
Keywords
}

Freedom of disposition by will; Inability to inherit; Person with disability; tutor; representative curator. 


\section{SUMARIO}

I. INTRODUCCIÓN. II. SITUACIÓN ACTUAL Y PERSPECTIVAS DE REFORMA: LA PROHIBICIÓN DEL ARTÍCULO 753 CC, COMO TAL, SE MANTIENE: 1. Inicial restricción de la prohibición. 2. Extensión posterior de la prohibición en dos niveles. III. RATIO IURIS DEL ACTUAL ARTÍCULO 753 Y SU POSIBLE PRUEBA EN CONTRARIO. IV. PECULIARIDADES DE ESTA PROHIBICIÓN. V. RAZONES POR LAS CUALES SE DEBERÍA PRESCINDIR DE ESTA PROHIBICIÓN Y BUSCAR OTRAS VÍAS. VI. PROPUESTAS. VII. ACERCA DEL PAPEL DE LA INTERVENCIÓN NOTARIAL. BIBLIOGRAFIA.

\section{INTRODUCCIÓN'}

Probablemente el título de este artículo suponga una toma de postura previa sobre dos cuestiones: la primera, que lo que el Código Civil encuadra dentro de la capacidad para suceder por testamento (sección primera del capítulo II del libro III) y que comúnmente se conoce como incapacidades relativas, son, ni más ni menos, prohibiciones legales, con todo lo que ello supone; la segunda, que esta es una de esas figuras respecto de las que conviene plantearse su futuro. Y es que en una época en la que todavía somos herederos del prohibido prohibir de finales de los sesenta, $\mathrm{y}$, sobre todo, en la que se trata de potenciar al máximo la autonomía y la decisión libre del individuo, no deja de chirriar que el legislador siga teniendo una desconfianza como la que late en estas figuras hacia ciertas personas o instituciones, y, lo que es más grave, hacia el propio valor de la voluntad del testador. El legislador parece no creerse que hay situaciones en las que, pese a todo, el testador puede querer dar determinada dirección a sus bienes, y decide por él diciendo sencillamente que no puede hacerlo. En un afán de sobreprotección, se presume iuris et de iure

1 Trabajo realizado en el marco del Proyecto del Ministerio de Economía y Competitividad DER 2016-75342-R «Prospectiva sobre el ejercicio de la capacidad: la interrelación entre las reformas legales en materia de discapacidad y menores» (IIPP De Salas Murillo/Mayor del Hoyo). 
—aunque no se diga así expresamente- la captación de voluntad del testador, en ocasiones de forma difícilmente justificable.

Esto, que no plantea excesivos problemas en el caso de la prohibición para suceder por parte de los notarios autorizantes del testamento (siempre se puede acudir a otro para posibilitar que el notario que se quiera designar como sucesor pueda serlo), sí que los plantea en lo relativo a las personas que se relacionan con el testador por motivos, por ejemplo, de lo que genéricamente podemos denominar su atención religiosa en la etapa final de la vida, y, sobre todo - y para mí es una de las cuestiones de más flagrante anacronismo- - en la persona que, en muchos de los casos, abnegadamente y sin recibir contraprestación suficiente a cambio, asume su guarda legal. Los tiempos han cambiado y la figura del oscuro tutor que se aprovecha de la situación del pupilo, propia de algunas novelas decimonónicas, es mucho menos frecuente que el problema real actual, que es justamente el antagónico: muy difícilmente se encuentra quien quiera asumir la tutela. Y, sobre todo, el discurso tiene que ser muy otro cuando, a resultas de la implantación en nuestro ordenamiento jurídico de la Convención Internacional sobre los Derechos de las Personas con Discapacidad ${ }^{2}$ (en adelante, la Convención), la voluntad de la persona asume el mayor espacio posible siempre que reciba los correspondientes apoyos. ¿Ha de extenderse entonces esta prohibición a quien presta dichos apoyos? Porque llegado el caso, el peligro de captación de voluntad en el momento de la prestación del apoyo puede ser el mismo.

$\mathrm{Y}$ ya puestos, si hemos de presumir captación de voluntad, ¿acaso no habríamos de presumirla en casos de testador de edad avanzada que deja bienes a la persona que le cuida? Y sin embargo aquí el legislador no interviene ex ante.

En este trabajo pretendo crear interrogantes al hilo de uno de los ejemplos citados: la prohibición de suceder del art. 753 respecto a quienes ejercen la guarda legal mediante las actuales tutelas o curatelas, o, en el caso de aprobarse la reforma del Código Civil y la Ley de Enjuiciamiento Civil para adaptarse a la Convención, las tutelas de menores o las curatelas representativas de adultos con discapacidad: y ello, no tanto por proteger un interés o expectativa de tutores o curadores, sino desde la óptica del protagonista - el testador con discapacidad- como manifestación de la «capacidad jurídica en igualdad de condiciones con los demás en todos

2 Convención Internacional sobre los Derechos de las Personas con Discapacidad, adoptada por Naciones Unidas el 13 de diciembre de 2006 y ratificada, junto con su Protocolo Facultativo, por España (BOE, n.o 96 y n.o 97, de 21 y 22 de abril de 2008). 
los aspectos de la vida», proclamada en el art. 12.2 de la Convención ${ }^{3}$. Llamativamente, el legislador, que está dispuesto a avanzar en la adaptación de nuestro sistema a dicho artículo, sigue anclado en este negativo prejuicio: así, en el texto del Anteproyecto de Ley por la que se reforma la legislación civil y procesal en materia de discapacidad, aprobado por el Consejo de Ministros el 21 de septiembre de $2018^{4}$, no solo no se elimina la prohibición, sino que se extiende a las personas o entidades que gestionan los servicios residenciales o asistenciales de las personas con discapacidad; personas de las que se presume, nuevamente sin prueba en contrario, que van a ejercer la influencia indebida frente a la cual el Estado tiene la responsabilidad de proveer las correspondientes medidas y salvaguardias (véase el art. 12.4 Convención). Parece que el modo de salvaguardar no es otro, en este punto, que prohibir.

Adelanto que, en mi opinión, la salvaguarda ha de ir por otras vías diferentes de la prohibición, como la intervención notarial y, sobre todo, la prestación de apoyos exquisitamente respetuosa de la libertad del testador, y, en último término, por la impugnación a posteriori, posible por otra parte, para el testamento otorgado por cualquier persona, tenga discapacidad o no, sobre la base de algunas de las vías que mencionaré.

3 El art. 753 CC, que centra este trabajo, es aplicable también al pupilo menor de edad, pero por los motivos que expongo en el texto me limitaré al campo de las personas con discapacidad sometidas a estas medidas.

4 El Anteproyecto fue publicado en el punto de acceso a los trámites de consulta pública previa y de audiencia e información pública del Ministerio de Justicia el 26 de septiembre de 2018. Se puede consultar, entre otros en https://bit.ly/35pIvQB.

En el intervalo entre el envío y la revisión de este artículo, el Gobierno aprobó otra versión del Anteproyecto — con fecha del 14 de enero de 2019- que conserva el tenor del artículo que se expondrá en el cuerpo de texto: el Anteproyecto de Ley por la que se reforma la legislación civil y procesal para el apoyo a las personas con discapacidad en el ejercicio de su capacidad jurídica, procedente, en este caso, de los ministerios de Justicia y Sanidad, Consumo y Bienestar Social.

El Real Decreto 129/2019, de 4 de marzo, por el que se produjo la disolución del Congreso de los Diputados y del senado, conllevó la paralización de su tramitación; paralización que se prolonga tras el Real Decreto 551/2019, de 24 de septiembre, de disolución del Congreso de los Diputados y del Senado y de convocatoria de elecciones. dado que era un tezto proveniente de la Comisión General de Codificación del Ministerio de Justicia que se había trabajado con operadores sociales, previsiblemente será la base en la siguiente legislatura. 


\section{SITUACIÓN ACTUAL Y PERSPECTIVAS DE REFORMA: LA PROHIBICIÓN DEL ARTÍCULO 753 CC, COMO TAL, SE MANTIENE}

La cuestión de la que se va a tratar se enmarca en una doble coordenada: la de los límites a la libertad para testar, y la de la perspectiva del derecho al libre desarrollo de la personalidad (art. $10 \mathrm{CE}$ ) de la persona con discapacidad.

Respecto a la primera de ellas, se relaciona tanto con la libertad entendida en sentido negativo, como posibilidad de disponer del propio patrimonio, sin que otros, como, por ejemplo, el Estado, a través de la imposición de cuotas forzosas o impidiendo ciertas disposiciones —en lo que hace a este trabajo, las prohibiciones para suceder-, se interpongan en esa actividad, como con la libertad positiva, que implica la de tomar las propias decisiones con plena validez jurídica, por inusuales, caprichosas o extrañas que estas sean ${ }^{5}$. Y hablo de límites a la libertad para testar, en el sentido de que el contenido del acto de última voluntad ha de ser fruto del libre albedrío y libre de cualquier vicio de la voluntad ${ }^{6}$. En el análisis de estas cuestiones, la doctrina se ha centrado fundamentalmente en el tema de la legítima y de las reservas como límites a esta libertad, aunque también en puntos concretos como, dentro del posible contenido del testamento, la posibilidad de imponer condiciones a los sucesores, lo que puede afectar la libertad e incluso los derechos fundamentales de estos (Vaquer Aloy, 2015a). En este trabajo se va a abordar uno de los posibles límites impuestos por el sistema a la posibilidad de disponer mortis causa.

Sin embargo, y teniendo todo ello a la vista, es la segunda coordenada la que va a centrar mi atención, para plantear si, a la vista de la interpretación que impone la Convención, es justificable el mantenimiento de esta cortapisa a la libertad para testar de una persona por el solo hecho de que tenga una discapacidad. No soy ajena a que la voluntad del testador, base y justificación de la libertad de testar, es algo que puede ser objeto de influencias indebidas y de manipulaciones, sobre todo en períodos o situaciones de especial vulnerabilidad. Pero también es cierto, como recuerda la STS de 15 de marzo de 2018, en sentencia de Pleno (n. ${ }^{\circ}$ 146/2018, ponente: Parra Lucán), que «el principio de presunción de capacidad, que ya resultaba de nuestro ordenamiento (art. $10 \mathrm{CE}$, art. 322 Cc., art. $760.1 \mathrm{LEc}$ ), ha quedado reforzado por la Convención [...] [que] proclama como objetivo general el de promover,

\footnotetext{
La distinción en Torres García y García Rubio (2014: 17).

6 Como diferente de la libertad de testar, por la cual el causante puede elegir otorgar testamento o pacto sucesorio o no otorgar ningún negocio mortis causa; la diferencia ha sido desarrollada ampliamente por Vaquer Aloy (2018).
} 
proteger y asegurar el goce pleno y en condiciones de igualdad de todos los derechos humanos y libertades fundamentales por todas las personas con discapacidad así como promover el respeto de su dignidad inherente (art. 1)» ${ }^{7}$. Hay que partir, por tanto, y tras la Convención con mayor razón, de este principio de capacidad — tomando la distinción del profesor Vaquer Aloy-para testar y de testar como manifestación y afirmación de la dignidad inherente a la persona.

Pues bien, es en este marco donde nos seguimos encontrando con un artículo, el $753 \mathrm{CC}^{8}$, que, tras la reforma efectuada por la Ley Orgánica 1/1996, de 15 de enero, dice:

Tampoco surtirá efecto la disposición testamentaria en favor de quien sea tutor o curador del testador, salvo cuando se haya hecho después de aprobadas definitivamente las cuentas o, en el caso en que no tuviese que rendirse éstas, después de la extinción de la tutela o curatela. Serán, sin embargo, válidas las disposiciones hechas en favor del tutor o curador que sea ascendiente, descendiente, hermano, hermana o cónyuge del testador?

Por su parte, el texto del anteproyecto en tramitación dispone:

7 El recurso de casación debía resolver si una persona sometida a curatela para la realización de actos de disposición necesitaba contar con la intervención para los actos de disposición mortis causa o si, caso de apreciarse su capacidad para testar con los requisitos del art. $665 \mathrm{CC}$, podía otorgarlo por sí sola. El Tribunal Supremo se inclina con claridad por lo segundo, sobre la base de argumentos, entre otros, como que «no cabe basar la falta de capacidad para testar ni por analogía ni por interpretación extensiva de otra incapacidad», o que «atendiendo a su diferente naturaleza y caracteres, la disposición de bienes mortis causa no puede equipararse a los actos de disposición inter vivos y existe una regulación específica para el otorgamiento de testamento por las personas con discapacidad mental o intelectual», complementado, claro está, con las cautelas que la propia legislación actual prevé para la aseveración de la capacidad in actu para otorgar dichos actos.

8 Artículo que no tiene antecedentes en nuestro derecho histórico: como explica Díaz Alabart, es en el anteproyecto de 1882-1888 donde aparece el artículo equivalente al actual 753, que, salvo la utilización del término pupilo en vez del de administrado, es una traducción exacta del art. 769 del Código italiano de 1865 (Díaz Alabart, 1987: 306 y ss.).

9 El texto inicial decía: «Tampoco surtirá efecto la disposición testamentaria del pupilo a favor de su tutor hecha antes de haberse aprobado la cuenta definitiva de éste, aunque el testador muera después de su aprobación. Serán, sin embargo, válidas las disposiciones que el pupilo hiciere en favor del tutor que sea su ascendiente, descendiente, hermano, hermana o cónyuge». 
Tampoco surtirá efecto la disposición testamentaria en favor de quien sea tutor o curador representativo del testador, salvo cuando se haya hecho después de la extinción de la tutela o curatela.

Será nula la disposición hecha por las personas que se encuentran internadas por razones de salud o asistencia, a favor de sus cuidadores que sean titulares, administradores o empleados del establecimiento público o privado en el que aquellas estuvieran internadas. También será nula la disposición realizada a favor de los citados establecimientos.

Las demás personas físicas que presten servicios de cuidado, asistenciales, o de naturaleza análoga al causante, solo podrán ser favorecidas en la sucesión de éste si es ordenada en testamento notarial abierto.

Serán, sin embargo, válidas las disposiciones hechas en favor del tutor, curador o cuidador que sea pariente con derecho a suceder $a b$ intestato.

Como vemos, el punto de partida es el mismo: la prohibición, pero en el texto proyectado, inicialmente restringida y a continuación extendida a dos niveles de diferente entidad.

\section{INICIAL RESTRICCIÓN DE LA PROHIBICIÓN}

Excluida de nuestro campo la mención al tutor, pues este cargo se reserva en el texto proyectado únicamente para la tutela de menores ${ }^{10}$, la restricción inicial viene dada por circunscribirlo al curador representativo. La discusión doctrinal y jurisprudencial habida hasta ahora sobre el ámbito subjetivo del art. 753 CC había apreciado, por ejemplo, que, a diferencia de lo previsto en los arts. 752 y 754 CC, no cabe extender la incapacidad para suceder a los parientes del tutor o curador (a menos que hayan sido empleados como personas interpuestas [véase STS de 11 de marzo de 1911]), o a otros guardadores legales, como el defensor judicial ${ }^{11}$; incluso algún autor aprecia «consenso en

10 «[...] la tutela, con su tradicional connotación representativa, queda reservada para los menores de edad que no estén protegidos a través de la patria potestad, mientras que el complemento de capacidad requerido por los emancipados para el ejercicio de ciertos actos jurídicos será atendido por un defensor judicial», Exposición de motivos, IV, del Anteproyecto de Ley.

11 Y ello, en contraste con el tenor de los arts. 752 y 754 . Véase Martínez de Aguirre (2018: 86), que manifiesta dudas en relación al acogedor permanente con funciones tutelares (art. 173 bis 2. ${ }^{a} \mathrm{CC}$ ), respecto del que sí aprecia posible peligro de captación de voluntad. García Cantero encuentra dudas para extender la prohibición al tutor exclusivamente de la persona, que es del todo ajeno a la administración del patrimo- 
que el precepto sólo es aplicable a la tutela en sentido estricto pero no a otros cargos tutelares» ${ }^{12}$. Sin embargo, el tenor literal del precepto aún vigente alude claramente al curador, y ello aunque sus funciones puedan ser tan puntuales $o$ limitadas que difícilmente puedan propiciar esa influencia indebida ${ }^{13}$. El texto del anteproyecto parece haber asumido esta última crítica cuando circunscribe la prohibición a los curadores con funciones representativas, que actuarán en casos de mayores necesidades de apoyos y en los que, por ende, hay mayor posibilidad de influencia. Desde el otro polo personal, y a diferencia del art. 221.1. ${ }^{\circ}$, no cabría proyectar la prohibición al testamento de los causahabientes del tutelado (ello, si en las liberalidades a las que alude este art. 221.1. ${ }^{\circ}$ se incluyen, con la doctrina mayoritaria, las mortis causa).

$\mathrm{Y}$ una restricción adicional a la inicial viene dada porque el tradicional levantamiento de la prohibición respecto al tutor o curador que fuera ascendiente, descendiente, hermano, hermana o cónyuge del testador se extiende ahora a los parientes con derecho a suceder ab intestato ${ }^{14}$.

\section{EXTENSIÓN POSTERIOR DE LA PROHIBICIÓN EN DOS NIVELES}

El nivel más duro extiende la prohibición a los establecimientos públicos o privados en los que el testador estuviera internado por razones de salud o asistencia (y, por tanto, al margen de que esté sometido o no a una curatela) y a los cuidadores que sean titulares, administradores o empleados de dicho es-

nio del pupilo, por lo cual no incurriría en actividad sospechosa si el que adquiere o enajena bienes es únicamente el tutor de los bienes. Él se inclinaría, sin embargo, a extenderle la prohibición, ya que la función y el cargo tutelar constituyen una unidad difícil de escindir; lo que cada tutor gestiona (persona o patrimonio) repercute en la gestión del otro, al menos en la apariencia frente a terceros, y de hecho se traducirá en habitual relación entre ambos. Nuevamente, la reflexión es al hilo del art. 221, pero plenamente aplicable a las reflexiones aquí vertidas.

12 Trujillo Díez (2016: 928), actualizado por Marín López.

13 Lo cual ha sido objeto de críticas por parte de la doctrina, como pone de manifiesto García Rubio (2016b: 609). Pese a ello, la Propuesta del Código civil de la Asociación de Profesores de Derecho Civil (2018) mantiene la incapacidad relativa de «tutor o curador» (art. 461-9), salvo que sea ascendiente, descendiente, cónyuge o hermano del causante, si bien se contrapesa con la posibilidad que luego veremos de que puedan suceder si la designación se hace en testamento notarial abierto o en pacto sucesorio.

14 Nótese, sin embargo, que sigue quedando fuera la pareja estable no casada, que en no pocas ocasiones será quien asuma esta función. 
tablecimiento ${ }^{15}$. Con ello se acoge la crítica hecha al texto actual del artículo, que no alude a quienes frecuentemente tienen, por su cercanía con la persona internada, muchas más posibilidades de captar su voluntad o de influir indebidamente en ella. El criterio es, por tanto, que el estar en la residencia parece incrementar considerablemente el peligro de captación de voluntad, y por ello se le aplica el mismo régimen que al curador representativo.

Un nivel más suave, que, sobre la base de la misma argumentación que acabo de describir, extiende la incapacidad al resto de los cuidadores no residenciales - las demás personas físicas que presten servicios de cuidado, asistenciales, o de naturaleza análoga al causante-, les permite, sin embargo, ser favorecidos en la sucesión si esta es ordenada en testamento notarial abierto. La intervención del notario en este tipo de testamentos sospechosos, aunque aquel no tenga la formación específica propia de un forense, permite, o por lo menos hace más fácil, «detectar si el testador está sometido a alguna presión o sugestión; una entrevista a solas con preguntas sobre el contenido de su testamento y las razones de ese contenido pueden aflorar la existencia de una voluntad captada» (Vaquer Aloy, 2015b: 368), o de una influencia indebida proscrita por la Convención. A ello hay que sumar el papel del notario en la apreciación de la capacidad legal exigida para el otorgamiento del testamento, de modo que cumple una doble función tuitiva (Guilarte Martín-Calero, 2016: 89).

La mención a los cuidadores, realidad numéricamente creciente en nuestra sociedad, era reclamada desde hace tiempo por la doctrina ${ }^{16}$, y había sido ya atendida por la legislación catalana, que trata ambos casos (cuidadores en residencias y en domicilio) con el mismo criterio: pueden ser favorecidos en la sucesión siempre que la designación se haga en testamento notarial abierto o pacto sucesorio (art. 412-5.2 Código Civil de Cataluña, en adelante, CCC) ${ }^{17}$.

15 Y ahí, en lugar de, como en el párrafo primero, continuar con la tradición de predicar simplemente que no surtirán efecto las disposiciones que se hagan a su favor, afirma su nulidad.

16 Resume bien la situación Cabezuelo Arenas (2015) al decir: "A estas alturas resulta obsoleto que el Código Civil se preocupe exclusivamente por presiones ejercidas por confesores y no repare en personas vulnerables que dependen de sus cuidadores. ¿Acaso no se encuentra más inerme el testador cuando su bienestar está en manos de estos últimos? En nuestro Código no existe una regulación ad hoc para estos casos. De manera que las respuestas de nuestro legislador, se alejan progresivamente de la realidad».

17 «Las personas físicas o jurídicas y los cuidadores que dependen de las mismas que hayan prestado servicios asistenciales, residenciales o de naturaleza análoga al causante, en virtud de una relación contractual, solo pueden ser favorecidos en la sucesión de este si es ordenada en testamento notarial abierto o en pacto sucesorio». No obstante, 
Conviene advertir aquí que el legislador catalán optó por prohibir que quien desempeña estos servicios pueda ser al mismo tiempo cargo tutelar, considerándolo como una exclusión por conflicto de intereses (art. 222-17 CCC: «1. No pueden ser titulares de la tutela ni de la administración patrimonial, ni ejecutoras materiales de las funciones tutelares [...], las que, en virtud de una relación contractual, presten servicios asistenciales, residenciales o de naturaleza análoga a la persona protegida. 2. No obstante lo establecido por el apartado 1, ante circunstancias excepcionales por necesidades de la persona tutelada, la autoridad judicial puede autorizar a las entidades tutelares a prestar servicios asistenciales y residenciales»), asumiendo así la propuesta de importantes sectores del sector de deslindar funciones para no ser juez y parte $^{18}$.

Pero volviendo al punto de partida, este es de prohibición, sin prueba en contrario y sin vías alternativas de escape, para los curadores representativos no familiares. Y esta es la línea también del Código Civil catalán, denominándola «inhabilidad sucesoria» (art. 412-5.1.d CCC), del «tutor, antes de la aprobación de las cuentas definitivas de la tutela, salvo que sea ascendiente, descendiente, cónyuge o hermano del causante». Es en el art. 412-5-2 CCC donde establece, para las personas físicas o jurídicas y los cuidadores que dependen de las mismas que hayan prestado servicios asistenciales, residenciales o de naturaleza análoga al causante, en virtud de una relación contractual, la posibilidad de ser favorecidos en sucesión ordenada en testamento notarial abierto o en pacto sucesorio.

Se atreve a dar un paso más, en mi opinión en la vía más adecuada, la Propuesta del Código civil de la Asociación de Profesores de Derecho Civil (en adelante, PCC) ${ }^{19}$, que, manteniendo la «incapacidad relativa» de tutor y curador (art. 461-9), admite, precisamente en el caso del tutor y el curador, que es

algunos autores se inclinan por una interpretación extensiva que afecte a los allegados al testador; véanse Vaquer Aloy (2013: 1810), y Arroyo i Amayuelas y Anderson (2013: 1710-1711).

Similar línea sigue el art. 461-10 PCC al disponer: «Las personas físicas o jurídicas que presten al causante servicios asistenciales, residenciales o de naturaleza análoga así como quienes trabajen para ellas, en relación de dependencia, solo pueden ser favorecidas en su sucesión si es ordenada en testamento notarial abierto o en pacto sucesorio".

$18 \mathrm{Y}$, de hecho, y aunque no esté impuesta como tal esta incompatibilidad en el Código Civil, es la línea de actuación seguida voluntariamente por muchas entidades: véase www.fundacionestutelares.org, que lo recoge como uno de sus principios.

19 Publicada por Tecnos, 2018. El art. 461-9 está dentro del título VI, capítulo I, sección 2. ${ }^{\text {, }}$ cuya autoría corresponde a A. Díaz Martínez. 
una «prohibición» que «no es de aplicación» cuando la disposición se ordene en testamento notarial abierto o en pacto sucesorio.

A continuación trataré de justificar los motivos por los cuales me parece necesario que el legislador reconsidere su postura a lo largo de la tramitación de esta necesaria reforma. Para ello, me detendré en la ratio iuris del actual artículo en relación con otras incapacidades relativas para suceder y con otras prohibiciones que, en diferentes ámbitos, pesan sobre los cargos tutelares, para finalizar con las razones de conveniencia y justicia desde la óptica de quien desempeña esos cargos, y de cumplimiento de los postulados de la Convención desde la perspectiva del testador con discapacidad.

\section{RATIO IURIS DEL ACTUAL ARTÍCULO 753 Y SU POSIBLE PRUEBA EN CONTRARIO}

Aunque solo sea numéricamente, es claro que en el Código Civil predominan las normas de carácter dispositivo, siendo excepcionales las de carácter imperativo, tanto las que imponen la realización de una conducta como las que la prohíben. Así y todo, no son pocas las prohibiciones contenidas en nuestro derecho civil, concebidas como veto que impide hacer a una persona actos que sin ellas podría llevar a cabo.

Prohibiciones que, en caso de que sean relativas, afectan a los dos polos personales: al que no puede donar a alguien y al que no puede recibir por donación de aquel; al que no puede comprar a determinada persona y, por tanto, al que no puede venderle, etc. Y ello, aunque en su literalidad se presenten solo desde el lado de quien las sufre (art. 221, $1 .^{\circ}$ y $3 .^{\circ}$, y art. 1459 CC, como prohibiciones de recibir liberalidades o comprar), o desde sus consecuencias para la disposición o negocio jurídico que las contraviene, que no surtirán efecto (art. $753 \mathrm{CC}$ ).

Todas ellas forman parte de lo que García Cantero describe como «una tupida red de acciones judiciales que, asépticamente, garantiza coram populo la protección del tutelado, cortando el paso a cualquier posibilidad de que ningún cargo tutelar se beneficie a costa de aquel» (García Cantero, 2016: 1038).

En el ámbito sucesorio, los arts. 752 a $754 \mathrm{CC}$ contienen varias incapacidades relativas para suceder por testamento, que funcionan como auténticas prohibiciones, implicando en su reverso una limitación al principio de libertad de disponer del sujeto activo ${ }^{20}$. En ellas se manifiesta, como explica García Ru-

20 No aprecio diferencias relevantes en el hecho de que los arts. 752 y 753 comiencen con las menciones «No producirán efecto las disposiciones testamentarias [...]»y 
bio, una solución ex ante que impide en todo caso la eficacia de la disposición a favor de determinadas personas que, por su peculiar relación con el testador, pueden influir en su voluntad de modo pernicioso (García Rubio, 2016a: 605).

La ratio iuris de estas prohibiciones es, por tanto, evitar la captación de voluntad del testador, que, por las circunstancias que rodean los supuestos contemplados en estos artículos, es más fácil que se produzca que en otros escenarios. El Código proyecta sobre estas circunstancias una suerte de tacha, o por lo menos de sospecha, de inmoralidad en los sucesores, presuntos captadores de voluntad, con el lógico correlato de la limitación de voluntad por parte del disponente, que se convierte, en el caso del art. 753, en una barrera infranqueable cuya justificación no es en absoluto clara.

La doctrina ha denunciado hace tiempo la aparente desproporción de estas prohibiciones para solucionar casos que bien podrían ir por la vía de la impugnación del testamento por vicios del consentimiento o por captación de la voluntad - aun con los problemas que supone la aceptación de la doctrina de la undue influence ${ }^{21}$ —, o, por lo menos, por admitir prueba en contrario, configurándose como presunciones iuris tantum ${ }^{22}$.

En relación con esto último, conviene preguntarse si el art. 753 CC contiene realmente una presunción sin prueba en contrario y, por tanto, una auténtica prohibición.

$\mathrm{Si}$ acudimos al artículo precedente —el art. 752-, la respuesta no es en absoluto clara, al menos tras la STS de 19 de mayo de $2015^{23}$ : en el caso resuelto por esta sentencia, se aprecia que, dándose los presupuestos del citado artículo (confesión, testamento posterior a aquella, disposición a favor del confesor durante la última enfermedad), se presume que el testador actuó bajo un estado de sugestión, «debiendo [y, por tanto, se parte de que se puede] ser desvirtuada dicha presunción por prueba en contrario». Se asume así la opinión de que si la finalidad de la norma es la preservación de la libre voluntad querida por el testador, debe descartarse la interpretación que, de un modo absoluto, aplica automáticamente el precepto sin posibilidad de prueba en contrario ${ }^{24}$. En contra, la opinión que aprecia en el tenor del artículo una

«Tampoco surtirá efecto la disposición testamentaria [...]», mientras el siguiente art.

754 esté redactado en claros términos de prohibición: «El testador no podrá disponer [...]». Su finalidad y consecuencias son equiparables.

21 Véase, por todos, la exposición de Vaquer Aloy (2015b).

22 Véanse los comentarios al art. 752 CC de Díaz Alabart y García Rubio, cits.

23 Comentada por Cabezuelo Arenas en op. cit.

24 Díaz Alabart (1987: 116) y Cabezuelo Arenas, cit. Para la compatibilidad del art. 752 con interpretaciones por analogía o interpretación extensiva, véanse los casos descritos por Cerdeira Bravo de la Mansilla (2012: 1037). 
prohibición de carácter absoluto, que limita completamente la libertad del testador, incluso aunque se probara que actuó libre, conscientemente y por propia iniciativa ${ }^{25}$.

No ha habido, hasta lo que yo sé, un pronunciamiento jurisprudencial similar para el art. 753 CC, y parece que sigue sin aceptarse la posibilidad de que la disposición a favor del tutor pueda perfectamente haber sido realizada por causas ajenas al prevalimiento de este ${ }^{26}$.

Ello concuerda, al menos en parte, con la imposibilidad de considerar válidos los actos prohibidos por la sentencia de modificación de la capacidad de obrar, incluso aunque se probara la aptitud natural de su autor en el momento de su realización.

Efectivamente, así como —en tanto se mantenga el sistema actual, claro está - rige una presunción de capacidad de la persona mientras dicha capacidad no haya sido modificada por sentencia, una vez que lo ha sido, se presume que la persona es incapaz para el acto o actos en cuestión, de forma que, aunque en ese momento tuviera aptitud o capacidad natural para realizar ese acto, de entrada este sería inválido. De hecho, solo son válidos los actos celebrados por estas personas cuando, por ser actos personalísimos y así preverlo el ordenamiento, se reconoce expresamente validez a los mismos si se acredita su capacidad natural para su realización, cumpliendo ciertos requisitos (para el testamento, los del art. 665 CC, o para el matrimonio, los del art. 56 CC). Rigidez del sistema en aras de la seguridad jurídica, que en ocasiones ignora la realidad, pero que hasta ahora ha sido comúnmente aceptada por considerar dicha seguridad jurídica como valor superior. Amén de que la aplicación del régimen de la anulabilidad a dichos actos permite su confirmación tanto si efectivamente se quiere acomodar a la realidad de respeto a la decisión de su autor (si en el momento tenía la citada aptitud natural para su realización) como si, al margen de ello, el representante legal considerase que era beneficioso para el incapacitado.

Decía que la concordancia entre ambas situaciones es solo parcial, y es precisamente en comparación con las posibilidades que acabo de exponer, por

25 O’Callaghan Muñoz (2000: 532). En el mismo sentido, García Rubio (2016a: 605), que considera que la STS de 19 de mayo de 2015 se equivoca en este punto.

26 Trujillo Díez (2016: 928), actualizado por Marín López, ya manifestaba su extrañeza de que ni doctrina ni jurisprudencia parecieran considerar esta posibilidad. Y es que ha de advertirse que, con carácter general, la jurisprudencia sobre estos artículos es bastante escasa, lo que puede traslucir una escasa litigiosidad; ahora bien, que la litigiosidad sea escasa puede obedecer a motivos de muy diversa índole, no necesariamente a que se trate de preceptos que susciten un consenso o adhesión generalizados entre sus destinatarios. 
las que se manifiesta la prohibición contenida en el art. $753 \mathrm{CC}$, y constituye una previsión mucho más cerrada y rígida en aras de lo que el legislador ha considerado como mejor opción para proteger a la persona con discapacidad.

\section{PECULIARIDADES DE ESTA PROHIBICIÓN}

Respecto a las incapacidades para suceder de los arts. 752 y 754 CC, además de lo visto sobre la posible prueba en contrario y la extensión de la prohibición a los familiares de los sujetos en ellas contemplados, existen otras diferencias que a mi modo de ver hacen merecedor de un tratamiento especial a este artículo.

En primer lugar, lo que diferencia en la práctica el supuesto del art. 753 del resto de las prohibiciones de suceder es que el testador no tiene ninguna otra alternativa en este caso: así como en principio, y salvo casos de urgencia o circunstancias variadas que lo hicieran imposible, cabría acudir a otro notario a otorgar testamento o incluso hacerlo ológrafo, o a otro confesor, para poder favorecer a estos por vía testamentaria, el sometido a tutela o curatela carece, por motivos que no es necesario explicitar, de esta posibilidad.

En segundo lugar, sin menosprecio alguno de la labor del notario o del confesor, es probable que el testador tenga muchos más motivos para agradecer las atenciones y cuidados prestados en vida por el tutor o el curador, que, en muchas ocasiones, atienden a la persona de un modo mucho más generoso y cercano que sus propios familiares.

También hay diferencias con otras prohibiciones que pesan sobre el tutor o curador (arts. 221 y 1459 CC). En efecto, sobre la misma base de desconfianza que justifica las incapacidades para suceder, el Código prohíbe «a quien desempeñe algún cargo tutelar [...] adquirir por título oneroso bienes del tutelado o transmitirle por su parte bienes por igual título» (art. 221.3. ${ }^{\circ} \mathrm{CC}$ ), que se concreta, en sede de compraventa, en la prohibición de «adquirir por compra, aunque sea en subasta pública o judicial, por sí ni por persona alguna intermedia [...] los bienes de la persona o personas que estén bajo su guarda o protección» (art. 1459.1. $\left.{ }^{\circ} \mathrm{CC}\right)$.

Pese a que en estos casos el sometido a tutela o curatela recibiría a cambio una contraprestación y el hipotético perjuicio sería menor, la prohibición se fundamenta en el presunto - también aquí sin prueba en contrario- conflicto de intereses presente en la autocontratación que se produce al vincular con una sola declaración de voluntad dos patrimonios distintos entre los que existe conflicto de intereses. Esa misma idea ha impedido, $v$. gr., la inscripción registral de negocios jurídicos tales como la partición otorgada por una perso- 
na que es a la vez defensor judicial del heredero menor de edad y apoderado del cónyuge viudo (RDGRN 26 de septiembre de 1951) ${ }^{27}$.

El anteproyecto mantiene esta prohibición del art. 1459.1 para «los que desempeñen cargo de tutor o curador» respecto a "los bienes de la persona o personas a quienes representen». Llama la atención que aquí no se aclare que se trata del curador representativo, que es respecto al que se produciría conflicto de intereses por el autocontrato. Si no es un curador de este tipo, sino solo de los que presta apoyos, y la persona con discapacidad tiene la capacidad para decidir sobre esa donación, ¿por qué extenderle esa prohibición? Porque posiblemente piensa el legislador que en la prestación del apoyo para dicha acción (la compraventa) se dará la misma captación de voluntad o influencia indebida.

Más cercana al supuesto del art. 753 CC, la prohibición de recibir liberalidades del tutelado o de sus causahabientes, mientras que no se haya aprobado definitivamente su gestión, a la que se refiere el art. 221.1. ${ }^{\circ}$ CC.

Para que este artículo fuera aplicable se entiende, en el caso del tutelado, que conserva la capacidad para disponer a título gratuito de bienes, posibilidad bastante improbable en el caso de que la sentencia le haya sometido precisamente a tutela (fuera de las donaciones de cantidades pequeñas en propinas, limosnas, etc.).

La referencia a la prohibición de recibir liberalidades de los causahabientes del tutelado — que no aparece en el art. 753 CC — parece pensada para evitar expedientes dirigidos a burlar dicha prohibición, como si el testador designara, $v . g r$., herederos a otras personas pero con la carga de hacer una liberalidad en el futuro al tutor. El escenario, en este último caso, sería distinto: el tutelado ya ha fallecido y sus causahabientes han recibido los bienes, y así como mediante el art. 221.1. ${ }^{\circ} \mathrm{CC}$ se trata de impedir la estratagema descrita, no hay razón suficiente que justifique que ellos no puedan dejar bienes vía testamentaria a la persona que fue tutor o curador de su causante: ni el extutor va a influir en su ánimo a la hora de testar si ellos no quieren, ni ellos son los sujetos de esta protección. Cosa distinta es que se pensara en institución inicialmente hecha a favor de otras personas pero con una sustitución — ya fuera vulgar o fideicomisaria - a favor del tutor, pues ello entraría, en mi opinión, en la ratio de la prohibición directa del art. 753 CC.

27 Este y otros ejemplos, en Gómez Gálligo (1992: 114 y 115). Todos ellos son supuestos de nulidad absoluta por existir autocontratación, elevada a la categoría de prohibición expresa por el art. 1459 CC, para los supuestos a que el mismo se refiere y en consecuencia determinantes de una calificación denegatoria como falta insubsanable. 
En contraste, en el art. 221 CC no aparece la excepción a la prohibición que favorece a los familiares que asuman estos cargos tutelares que sí aparece en el art. 753 CC.

Pese a estos desajustes entre unos y otros artículos, según García Cantero, no son contradictorios, y todos ellos — también el art. 1459 CC — pueden interpretarse conjuntamente de modo que resulten complementarios, constituyendo el art. $221 \mathrm{CC}$, a lo que parece, una formulación de los principios generales cuya interpretación puede ayudar a la exégesis de las restantes aplicaciones puntuales del mismo principio inspirador. Con todo, reconoce, la fórmula legal «recibir liberalidades» es un tanto imprecisa y lo suficientemente amplia como para comprender toda donación y acto de liberalidad tanto inter vivos y como mortis causa, si bien estos últimos son objeto también del art. 753, con algunos desajustes y falta de coherencia entre ambos preceptos (García Cantero, 2016: 1038 y 1041).

Existe, sin embargo, una diferencia, si se quiere un poco simple pero no por ello inexistente, y es que con la prohibición de liberalidades en vida al tutor o de compras sospechosas por parte de este se pretende no perjudicar en vida a la persona con discapacidad, pero tras su muerte el perjuicio a sus intereses, si es que lo hay, no se produce de la misma manera. Es verdad que, volviendo a la presunción de intereses espurios por parte del tutor, llevado al extremo, eso podría provocar una falta de cuidado e interés del tutelado que acelerara su muerte, y con ella, la adquisición de la herencia por parte de este. Pero ¿pensar en ese escenario reprochable y casi delictivo justifica el coartar la libertad de testar de la persona con discapacidad? Sinceramente creo que no.

Por lo demás, el texto del anteproyecto ha hecho desaparecer el contenido del actual art. $221 \mathrm{CC}$, refiriéndose este número a un tema distinto. Podría pensarse que es porque el texto del art. 753 CC propuesto acoge todas las liberalidades, pero no es así: solo se refiere a las deferidas vía testamentaria, por lo que parece que o bien el texto lo pasa por alto por error, o ha decidido prescindir de esta prohibición, lo cual es extraño siendo como se mantiene la de la compraventa, que potencialmente es menos peligrosa para la persona con discapacidad que la donación ${ }^{28}$.

28 Solo se hace referencia, en el art. $285.3 .^{\circ}$, a la necesidad de que «el curador que ejerza funciones de representación de la persona que precisa el apoyo necesita autorización judicial para [...]. 3. ${ }^{\circ}$ Disponer a título gratuito de bienes o derechos de la persona afectada, salvo los que tengan escasa relevancia económica y carezcan de especial significado personal o familiar». 


\section{RAZONES POR LAS CUALES SE DEBERÍA PRESCINDIR DE ESTA PROHIBICIÓN Y BUSCAR OTRAS VÍAS}

No es ninguna sorpresa constatar que factores como la reducción de la extensión de las familias o la insolidaridad propia de una sociedad competitiva y de alta velocidad como la actual provocan que sea muy difícil encontrar personas del entorno de las personas con discapacidad que, libre y desinteresadamente — pues la hipotética retribución del tutor o curador dista mucho de proporcionarle ganancias - , quieran asumir estos cargos. De hecho, las entidades públicas de tutela de adultos de las respectivas comunidades autónomas están generalmente sobresaturadas y cada vez es más importante el papel de las personas jurídicas privadas que se constituyen con este fin.

Es cierto que el texto del anteproyecto, consciente de este problema, no limita el montante de dicha retribución: «El curador tiene derecho a una retribución, siempre que el patrimonio de la persona con discapacidad lo permita, así como al reembolso de los gastos justificados y a la indemnización de los daños sufridos sin culpa por su parte en el ejercicio de su función, cantidades que serán satisfechas con cargo al patrimonio de la persona que precisa el apoyo» (art. 279).

Pero, además de que hoy por hoy es una retribución limitada, y porque, probablemente, en defensa de la persona con discapacidad no se fije en un montante excesivo, lo cierto es que la posibilidad que propongo en este trabajo parecería de justicia para quien ha ejercido esos cargos con interés y cuidado de la persona, máxime si la actitud de los familiares potenciales herederos $a b$ intestato ha sido de desinterés y abandono.

El rechazo a esta posibilidad viene, curiosamente, de muchas personas jurídicas que ejercen las tutelas, que quieren sentirse y ser libres, sin estar bajo la sospecha de que se postulan y en su caso aceptan estos cargos con ánimo de enriquecerse. Puedo entender esta loable actitud, pero me parece que las injusticias que se generan en ocasiones - favoreciendo, $v . g r$., a sobrinos lejanos que ni conocían al tutelado- neutralizan a los ojos de la sociedad estos miedos, a lo que habría que sumar que en el caso de muchas de las fundaciones tutelares privadas sus recursos propios son tan exiguos que necesitarán todos los recursos económicos que puedan allegar para seguir desempeñando su labor.

De todas formas, el argumento esencial es, a mi modo de ver, el de la libertad de testar de la persona con discapacidad como manifestación de la igual capacidad jurídica a la que alude el art. 12 de la Convención. Y parto de una premisa que quizá sea discutible pero que a mi entender es la más coherente: si se reconoce la posible testamentifacción activa, se ha de reconocer sin cortapisas distintas de las que tendría una persona sin discapacidad. Naturalmente tendrá los mismos límites que el resto, señaladamente en tema de legítimas, pero ni más ni menos. 
Y respecto a esta posibilidad de otorgar testamento, hay que destacar la postura de sentencias recientes que, pese al tenor actual de artículos como el art. 665 CC, niegan que se pueda privar por sentencia de ámbitos de actuación personalísimos como la testamentifacción activa o el matrimonio ${ }^{29}$, y el texto del anteproyecto concluye el art. 267 diciendo: «En ningún caso podrá incluir la sentencia la mera prohibición de derechos».

Todo ello, siempre que la persona con discapacidad tenga, en su caso con los necesarios apoyos, la capacidad para decidir acerca del destino mortis causa de sus bienes. Si carece de ella, evidentemente no podrá testar en su lugar su curador representativo, sino que o bien se abrirá la sucesión legal, o, si tiene padres, podrían estos establecer una sustitución ejemplar respecto a sus bienes, en la que se podrían tener en cuenta, además de sus preferencias (art. 12.4 de la Convención), los eventuales «derechos» sucesorios de los cuidadores de la persona con discapacidad. En su reciente monografía sobre este punto, afirma De Amunátegui que, desde el punto de vista del sustituido, mantener la teoría del testamento sustitutorio

[...] no implica restringir su capacidad de testar, ni atentar a sus derechos, sino precisamente permitir una expresión de sucesión voluntaria, atendiendo a las circunstancias presentes en cada situación, cediendo en todo caso si es posible el otorgamiento de testamento en intervalo lúcido. Cuando exista disposición válida del incapaz deja de ser eficaz la sustitución ejemplar que presenta en todo caso un carácter subsidiario ${ }^{30}$.

El motivo de fondo se encuentra en que la igual capacidad jurídica a la que alude el art. 12 de la Convención, que tendría como una de sus manifestaciones — aunque no se diga expresamente ${ }^{31}$ - la testamentifacción activa:

29 Entre otras, la STS de 8 de noviembre de 2017, que considera que las limitaciones a la capacidad para otorgar testamento y contraer matrimonio, adoptadas genéricamente, son contrarias a los principios que rigen la protección de las personas con discapacidad, o la STS de 7 de marzo de 2018, que afirma que el testamento es un acto personalísimo al que no puede extenderse la sentencia de incapacitación. Lo apuntaba ya la doctrina: véase el comentario al art. 665 CC de Álvarez Lata (2016), y doctrina allí recogida; también, en Guilarte Marín-Calero (2016: 88-89).

30 Todo ello en la reciente monografía sobre este punto de la profesora De Amunátegui Rodríguez (2018), donde se hace una acertada y exhaustivamente justificada propuesta sobre el mantenimiento y dotación de amplio alcance de esta figura. La cita es de la página 232.

31 Sí que se alude en el art. 12.5 de la Convención a cuestiones como la capacidad para ser propietarias y heredar bienes y controlar sus propios asuntos económicos, entre otros. 
posibilidad que requeriría, al igual que para las personas sin discapacidad, que tengan capacidad legal (14 años) y en el momento en que vayan a otorgarlo tengan entendimiento y voluntad suficiente para hacerlo ${ }^{32}$.

Evidentemente tienen que tener esa capacidad, a tenor de los actuales arts. 663.2, ${ }^{\circ} \mathrm{CC}$, que incapacita para testar al que «habitual o accidentalmente no se hallare en su cabal juicio», y $665 \mathrm{CC}$, que impone al «incapacitado por virtud de sentencia que no contenga pronunciamiento acerca de su capacidad para testar», y el necesario dictamen positivo de dos facultativos sobre dicha capacidad específica. Dictamen sin el cual el notario no puede autorizar el testamento, pero es dudoso que quede obligado a autorizarlo si, pese a ello, no aprecia la capacidad necesaria ${ }^{33}$.

El anteproyecto conserva la esencia de este juicio de capacidad si bien con una terminología más respetuosa con la Convención. El proyectado art. 663.2..$^{\circ}$ dice: «No pueden testar: [...] La persona que en el momento del otorgamiento tenga afectadas las facultades de discernimiento necesarias para ello», y, por su parte, respecto al art. 665 se propone el siguiente texto: «Si el que pretende hacer testamento se encontrara en una situación que hiciera dudar fundadamente al notario de su aptitud para otorgarlo, antes de autorizarlo, este designará dos facultativos que previamente le reconozcan y dictaminen favorablemente sobre dicha aptitud». Todo apunta a la necesaria intervención del notario para la validez de estos testamentos, como se dirá enseguida.

Continuando con la argumentación del motivo de fondo para eliminar la prohibición del art. $753 \mathrm{CC}$, dando toda su dimensión a la posibilidad de otorgar testamento por parte de la persona con discapacidad, debe tenerse en cuenta que hay ámbitos especialmente sensibles para la persona con discapacidad, como el sufragio activo, hasta ahora objeto de una importante restricción prevista en el art. 3.1.b) LOREG, que, sin embargo, acaba de ser eliminada por la Ley Orgánica 2/2018, de 5 de diciembre (eliminación que operará, además, ministerio legis, sin tener que impugnar una a una sentencias anteriores). En el mismo nivel de afirmación de dignidad de la persona, está el decidir qué destino quiere para sus bienes tras su muerte, y en la elección de ese destino, la protección y el paternalismo no se pueden volver en su contra impidiendo lo que él o ella quieren, a lo mejor con todas sus fuerzas: dejar los bienes a la persona física o jurídica que más y mejor se ha ocupado de ellos.

32 En este sentido, Gómez Laplaza y Díaz Alabart (2014: 545).

33 El tema, sin embargo, es discutido: me remito a los comentarios de Rodríguez Guitián (2016: 277-278) y Álvarez Lata (2016: 846). 
Si el criterio del «mejor interés de la persona con discapacidad» se considera abandonado e incluso en algunos sectores proscrito ${ }^{34}$, ¿por qué ha de decidir el legislador qué es lo mejor para él en este punto prohibiéndoselo $a$ priori? Si eliminamos la incapacitación como tal y de alguna manera revive, no la presunción de capacidad clásica, sino la consideración de la misma capacidad jurídica en su caso necesitada de apoyos para su ejercicio, ¿podemos prescindir de este postulado, así como del favor testamenti? Creo que sobre todo esto se debe reflexionar sin los perjuicios que arrastramos, fruto, muchas veces, de ideas preconcebidas y de miedo al cambio.

Ahora bien, quien escribe estas líneas comparte los reparos que muchos tienen frente a un ilimitado right to wrong de la persona con discapacidad, $\mathrm{y}$, por ello, entiendo que probablemente la mejor medida de apoyo para la toma de decisiones respecto al destino mortis causa de sus bienes, y en concreto en el caso de que vayan al tutor o curador, debería ser la intervención notarial.

$\mathrm{El}$ apoyo en estos casos tiene que ser exquisitamente respetuoso con el carácter personalísimo del testamento, siendo tan solo un mero consejo o asesoramiento que deje libre a la persona. En ningún caso puede tener contenido jurídico en sentido estricto, y en esto la STS de 15 de marzo de 2018 ha sido muy clara, al referirse al papel del tutor o curador a la hora de testar excluyendo el posible apoyo o intervención en los negocios jurídicos de disposición mortis causa del tutelado o curatelado: «[...] ni el tutor como representante legal puede otorgar testamento en lugar de la persona con capacidad modificada judicialmente ni el curador puede completar su capacidad cuando sea ella quien otorgue testamentom ${ }^{35}$.

Pero sin tener ese contenido de sustitución o complemento de capacidad en sentido jurídico, tampoco sería útil, y seguro que no se vería con buenos ojos desde fuera, que el apoyo, en versión asesoramiento para la toma de esta decisión, viniera, precisamente, de quien en el futuro se va a beneficiar de ella. Por eso, un tercero imparcial como es el notario puede cumplir perfectamente este papel de asesoramiento, haciéndose cargo mediante preguntas acertadas —ila necesaria formación de los notarios en este ámbito!- de cuál es la voluntad de la persona con discapacidad.

34 Se expone esta tendencia en De Salas Murillo, 2018.

35 Ya apuntaba con razón Guilarte Martín-Calero (2016: 88), antes de estas sentencias, que no parece oportuno imponer la asistencia del curador para el otorgamiento de testamento, que el autor realiza por sí mismo y por sí solo, al tiempo que recomienda limitar el otorgamiento a la forma notarial abierta, a la espera de la reformulación de los arts. 663.2 y 665 CC para adaptarse a los postulados de la Convención. 


\section{PROPUESTAS}

Ya he ido anunciado cuáles son mi postura y mi propuesta al respecto. Hago ahora una recapitulación añadiendo una referencia a la fase temporalmente previa al nombramiento de tutor o curador, o, en su caso, en el futuro texto, de curador representativo.

Respecto a la fase previa, ¿hay algún problema en las designaciones hechas a favor de quien luego resulta tener uno de estos cargos? El tenor literal del actual art. 753 CC plantea algunas dudas, pues si bien queda claro que quedan exentas de la prohibición y surten efecto las designaciones hechas «después de aprobadas definitivamente las cuentas o, en el caso en que no tuviese que rendirse éstas, después de la extinción de la tutela o curatela», el inciso «no surten efecto las disposiciones testamentarias en favor de quien sea tutor o curador del testador ${ }^{36}$, podría interpretarse en el sentido de hacer incapaz para suceder a quien en el momento de fallecer el testador fuera su tutor o curador, con independencia de que ostentara o no el cargo en el momento del otorgamiento del testamento. Lo cierto es que si lo que se quiere evitar es la captación de voluntad del testador, lo correcto es referirlo precisamente al momento de hacer la disposición testamentaria ${ }^{37}$. Pero es que, además, también lo sería, en mi opinión, aunque se hiciera una delación de autotutela (autocuratela en el anteproyecto), acompañada de una institución de heredero o legatario a favor del designado: no se aplicaría aquí la prohibición del art. 753 CC, aunque no se cuente entre las excepciones de los familiares nombrados en el mismo artículo. Y ello no solo por la interpretación restrictiva que entiendo que ha de darse a la prohibición contenida en este artículo, sino fundamentalmente por el respeto a la voluntad del otorgante de ambos documentos, como a continuación explicaré. Además, si, llegado el momento, el juez apreciara en este doble nombramiento una sospechosa intención en los intereses del designado - pensando, por los indicios que pudiera haber, que la captación de voluntad se había producido en esa fase previa a la redacción de los documentoslo que haría sería precisamente no nombrarle tutor, posibilidad que permite el art. $234 \mathrm{CC}$, cuando si bien parte en su párrafo primero de que para el nombramiento de tutor se preferirá: «1. ${ }^{\circ} \mathrm{Al}$ designado por el propio tutelado,

36 Inciso que se conserva en el art. 753.I del anteproyecto, de modo prácticamente idéntico en este aspecto: "Tampoco surtirá efecto la disposición testamentaria en favor de quien sea tutor o curador representativo del testador, salvo cuando se haya hecho después de la extinción de la tutela o curatela».

37 Así lo entiende García Rubio (2016b: 609), que afirma que la incapacidad solo se produce si el testamento se ha otorgado con posterioridad al nombramiento de tutor y antes de la rendición de cuentas (véase el art. 596 CC italiano vigente). 
conforme al párrafo segundo del artículo 223», en el párrafo segundo dispone: «Excepcionalmente, el Juez, en resolución motivada, podrá alterar el orden del párrafo anterior o prescindir de todas las personas en él mencionadas, si el beneficio del menor o del incapacitado así lo exigiere».

Es más, puede ser que precisamente en consideración al nombramiento como futuro o posible tutor (o curador en el anteproyecto) se le hubiere hecho una disposición testamentaria. Que el Código Civil contempla como aceptable esta situación queda claro cuando, justamente, lo que dispone es que si, llegado el caso, el llamado alega una excusa para no ejercer dicho cargo, «perderá lo que, en consideración al nombramiento, le hubiere dejado el testador» (art. $257 \mathrm{CC}$ actual, y, en similares términos, el art. 278 del anteproyecto). Pues bien, en mi opinión, desde el año 2003, esta consecuencia prevista en el art. 257 CC no puede limitarse a la delación hecha por los padres, ya que desde esa fecha el art. 223 CC incluye la posibilidad de que sea el propio interesado quien haga la designación (autotutela). Y esta interpretación sistemática la aplico tanto para lo positivo, es decir, la posibilidad de, incluso en un mismo documento, nombrar heredero o legatario a la misma persona de confianza a la que se le encomienda la eventual tutela o curatela, como para lo negativo: la extensión del efecto de pérdida de lo dejado en testamento ${ }^{38}$. Como el designado como eventual tutor o curador aún no ejerce ninguno de sus cargos cuando se le hace la designación testamentaria, no se vulnera la prohibición de la que trata este trabajo. Otra cosa, como he dicho, es que un juez escrupuloso optara, temeroso de un más que posible conflicto de intereses, por no nombrar tutor o curador a esa persona.

Todo ello sin olvidar la siempre presente posibilidad por parte del interesado de modificar el testamento a favor de personas diferentes, y de la impugnación a posteriori una vez abierta la sucesión.

Es verdad que esta posibilidad de la autotutela no estaba prevista ni cuando se aprobó el Código Civil ni cuando se reformó este artículo en 1996, pero no creo en ningún caso que el art. 753 CC deba interpretarse en el sentido de que es incapaz para suceder el que en el momento de fallecer el testador sea su tutor o curador.

38 De distinta opinión, para De Amunátegui Rodríguez (2019: 145), se trata de una regla restrictiva que no permitiría su aplicación por analogía para otros casos: propone como texto alternativo el de la propuesta de la Asociación de Profesores de Derecho Civil, que atenúa notablemente el rigor de la regla, y lo amplía a las autodelaciones (art. 174-14, 5: «El curador o tutor designado en testamento o en escritura pública que se excuse de la curatela o la tutela pierde lo que, en consideración al nombramiento, se le haya dejado por vía de herencia, legado o donación, siempre que del acto de disposición no se deduzca lo contrario. Si la excusa se produce de forma sobrevenida la autoridad judicial puede determinar la pérdida total o parcial atendiendo a las circunstancias del caso»). 
Y es más, si entendemos que la designación de autotutela ha de hacerse contando con la «capacidad de obrar suficiente» (art. 223.2), y que, en cualquier caso, para otorgar testamento, el notario autorizante ha de apreciar su capacidad -y lo lógico sería, en el escenario que he descrito, que también el testamento fuera notarial ${ }^{39}$ - , no hay justificación alguna para tratar de extender la prohibición de heredar. Máxime porque, en caso de ser así, el juez, al nombrarle tutor o curador, estaría privándole de una posibilidad a la que - a salvo de posibles cambios en el testamento cumpliendo las condiciones del art. 665 CC — estaría llamado, y, por su parte, salvo casos de encomiable desinterés por parte del designado, este posiblemente alegaría excusa para no aceptar el cargo tutelar. En ambos casos, no se cumpliría la voluntad de la persona que, no olvidemos, puede declarar merced a las vías que el actual ordenamiento le proporciona.

Pero la propuesta debería ir más allá de lo dispuesto en esa fase previa, para aceptar la posibilidad de esta designación cuando ya se ha nombrado el cargo tutelar, pero el testador cumple con los postulados del art. $665^{40}$ y otorga testamento notarial abierto.

Como describe perfectamente García Cantero ${ }^{41}$, en cita que, pese a su extensión, quiero reproducir aquí:

[...] respondiendo a una larga tradición, y a los datos de la experiencia, el legislador se ha propuesto, como ratio de la norma, a modo de una casi absoluta incomunicabilidad patrimonial y negocial entre el cargo tutelar y el pupilo pues se estima que ello ha de impedir, mientras dure el oficio tutelar, la ocasión de que se reiteren tradicionales formas de abusos, y, asimismo, se logrará que resplandezca ante terceros la

39 Doy por sentado, aunque como se sabe el tema se ha debatido por extenso (véase De Amunátegui Rodríguez, 2008), que el otorgamiento del documento de autotutela se hará en documento público: así se dice en el anteproyecto respecto a la autocuratela (art. 269): «Cualquier persona mayor de edad o menor emancipada, en previsión de que se produzca alguna de las circunstancias a las que se refiere el artículo 248 podrá, en escritura pública, proponer el nombramiento o la exclusión de una o varias personas determinadas para el ejercicio de la función de curador». Lo lógico es que el testamento que contenga las disposiciones a su favor se haga por esta misma vía, aunque en puridad no se exigiera la forma de testamento notarial abierto, según lo que propondré en el texto, dado que en ese momento aún no está sometido a curatela representativa.

40 Como antes hemos visto, tanto el actual art. 665 como el proyectado requieren que en la duda fundada sobre la aptitud para otorgar el testamento se designen dos facultativos que previamente le reconozcan y dictaminen favorablemente sobre dicha aptitud.

$41 \mathrm{Al}$ hilo de su citado comentario al art. $221 \mathrm{CC}$, pero con reflexiones plenamente aplicables aquí. 
transparencia de la gestión económica realizada por el cargo tutelar. Finalidades, sin duda, loables y prudentes en principio [...]. Sólo que todavía cabría preguntarse si el presupuesto sociológico de los oficios tutelares en pleno siglo xxi coincide mayoritariamente con el que se vivía en España al promulgarse el CC, e, incluso, al dictarse la vigente ley de 1983. Por de pronto la posible complicidad o confabulación previas entre el cargo tutelar y, en todo o parte, el entorno familiar del pupilo, ha desaparecido prácticamente o se ha dificultado en grado sumo ante la permanente presencia judicial en la actual tutela. Tal tipología del tutor suspectus resulta, más bien — y al trasluz del derogado sistema de tutela de familia—, propia de sociedades mayoritariamente rurales de bajo nivel cultural y herméticas al exterior. Por ello opino que hoy entre los aspirantes a cargos tutelares será harto difícil encontrar semejante complicidad o confabulación previas. [...]. Por lo demás, no será inhabitual, en la práctica, que el juez designe como cargo tutelar a persona que carezca de todo vínculo de amistad o, incluso, de todo tipo de relación con el pupilo.

Lo dicho lleva al autor a concluir, sin embargo, que en ocasiones puntuales podrían encontrar plena ratio las prohibiciones tipificadas, con ocasión de que el cargo tutelar "pueda realizar un buen negocio a costa del patrimonio del pupilo (hay que vender deprisa una finca valiosa de este en época de crisis, o un bien sobrante del patrimonio del cargo tutelar puede enajenarse todavía $a$ buen precio al pupilo)». Concluyendo que, en último término, "podría afirmarse que la puesta en funcionamiento de estas prohibiciones redundará en interés y beneficio de la institución misma que resulta, de este modo, prestigiada y socialmente valorada (así, todos los ciudadanos constatan que nadie va a enriquecerse a costa de menores e incapacitados)».

Comparto estas reflexiones de García Cantero, que enmarcan perfecta y realistamente el marco del que partimos, pero pienso, por las razones anteriormente expuestas, que la designación testamentaria tiene otros presupuestos, $y$, sobre todo, otras consecuencias, en aras de evitar los perjuicios en la vida de la persona con discapacidad, y que, por el contrario, el respeto a su decisión sobre el destino mortis causa de sus bienes, con las cautelas y apoyo que puede prestar la función notarial - $\mathrm{y}$ en este trabajo lo concreto en la posible opción a favor de su curador representativo, pero sería extensible a cualquier opción permitida por el ordenamiento a las personas sin discapacidad-, es una necesaria manifestación del ejercicio de su igual capacidad jurídica (art. 12 de la Convención).

\section{ACERCA DEL PAPEL DE LA INTERVENCIÓN NOTARIAL}

Una última y brevísima reflexión al hilo de la intervención notarial como medida de apoyo concreta que he propuesto como requisito para el abandono de la prohibición del art. 753 CC. 
Me parece que, en efecto, la intervención notarial puede justificarse tanto en su función, entendida en el sentido tradicional de enjuiciar la capacidad para autorizar el acto del que se trate - o en el más moderno de asegurarse en la medida de lo posible de que no hay influencia indebida-, como en el servir de marco para proporcionar las medidas de apoyo en el ejercicio de la capacidad, en nuestro caso, para la emisión de la voluntad testamentaria. En ese sentido el notario está llamado a ser uno de los agentes jurídicos prestadores de apoyos más eficaces.

Pero sentado esto, no se debe imponer su intervención más allá de lo imprescindible, y, en este sentido, permítaseme aquí un excursus al hilo precisamente del anteproyecto de ley en curso. Como es sabido, las nuevas tecnologías permiten la firma de documentos a través de medios que permiten «acreditar la autenticidad de la expresión de su voluntad y consentimiento, así como la integridad e inalterabilidad del documento» (en relación con los sistemas de firma admitidos por las Administraciones públicas, véase el art. 10.1 de la Ley 39/2015, de 1 de octubre, de Procedimiento Administrativo Común de las Administraciones Públicas). En esta línea, artículos del anteproyecto, como los 201, 203, 204, 213.1, 218.3 y 269, quizá deberían permitir otros medios, como la firma electrónica reconocida o cualificada, además de los allí previstos. Por otra parte - como se refleja en la nota a pie 38- ha sido cuestión muy debatida la forma en la que deben constar los apoderamientos preventivos: el anteproyecto exige escritura pública, tanto para las medidas de apoyo que el interesado adopte «en previsión de la concurrencia futura de circunstancias que puedan dificultarle el ejercicio de su capacidad jurídica en igualdad de condiciones con lo demás» (art. 251) como para la autocuratela (art. 269). Es verdad que cuando, en su momento, vía Ley 43/2003, se introdujeron las medidas predecesoras de aquellas, se exigía la «capacidad de obrar suficiente», y ello convenía que fuera apreciado por alguien, hoy no parece tampoco excesivamente justificado limitar su forma a la escritura pública, excluyendo otros modos que permitan acreditar de manera fehaciente la autoría de dichas declaraciones: no en vano, ámbitos muy sensibles como los documentos de instrucciones previas no tienen por qué constar en escritura pública. Y, de hecho, el texto propuesto en el anteproyecto para el art. $706 \mathrm{CC}$ permite que el testamento cerrado se redacte en soporte electrónico y se firme con firma electrónica reconocida. Cabría pensar en esta última posibilidad, incluso respecto al testamento ológrafo, para aquellas personas que tengan imposibilidad de escribir ${ }^{42}$, sin excluir el recurso a otros sistemas, como una

42 Pone objeciones Espino Bernell (2016: 393-394) en su tesis doctoral El testamento ológrafo. La importancia de la escritura y la firma del testador. El cotejo pericial de letras 
grabación de vídeo, aunque acaso pasara a transformarse en cosa distinta del testamento ológrafo.

Estas últimas líneas tan solo son unas pinceladas que van en la misma línea que justifica el hilo argumental de lo que he tratado de expresar en este trabajo: que el sistema - y aquí incluiría lo jurídico y lo tecnológico- debe tener los medios suficientes en su propia estructura para dar cauce a la autonomía de la voluntad y al libre desarrollo de la personalidad en el ámbito testamentario, conciliándolo con las exigencias de la seguridad jurídica propia y de terceros, sin necesidad de imponer más prohibiciones de las razonables.

Pues bien, la consecuencia coherente y honesta de tal declaración de libertad de testar debería ser la de diseñar su contenido y destinatario (libertad para testar): no tiene mucha justificación que se admita su capacidad para testar pero no para decidir a quién se dejan los bienes. El proteccionismo basado en la presunción de captación de voluntad no casa mucho, en mi opinión, con la afirmación de su libre desarrollo de la personalidad, ni la afirmación de su dignidad. Otra cosa es que haya que prestarle los correspondientes apoyos para asegurar en la medida de lo posible que no se producen esas influencias indebidas, como, por otra parte, ha de hacerse con cualquier persona, pero no prohibirlo a priori.

\section{Bibliografía}

Álvarez Lata, N. (2016). Comentario al art. 665. En B. Rodríguez-Cano (coord.). Comentarios al Código civil. Cizur Menor (Navarra): Aranzadi.

Arroyo i Amayuelas, E. y Anderson, M. (2013). Cambios sin rupturas en el Derecho civil catalán. En M. Cuena Casas, L. A. Anguita Villanueva y J. Ortega Doménech (coords.). Estudios de derecho civil en homenaje al profesor Joaquin José Rams Albesa (pp. 1699-1719). Madrid: Dykinson.

Asociación de Profesores de Derecho Civil (2018). Propuesta del Código civil. Madrid: Tecnos.

(la prueba caligráfica), al afirmar: «[...] si bien la firma digital tiene la condición de ser reconocida, amén de tener legalmente equivalencia funcional a la firma manuscrita, ello sólo puede pregonarse en relación a los actos configurados de modo electrónico. Por ello y pese a darse dicha equivalencia podemos considerar que la firma digital adolece el requisito esencial previsto en el art. 688.2 CC al no ser firma escrita por el testador conforme a dicha exigencia legal». He consultado la versión disponible en https://bit.ly/2B5pIMs. 
Cabezuelo Arenas, A. L. (2015). El problema de la validez del legado ordenado por la testadora a favor de institución religiosa de la que formaba parte su confesor (Art. 752 CC). Revista Aranzadi Doctrinal, 11, 81-89.

Cerdeira Bravo de la Mansilla, G. (2012). Analogía e interpretación extensiva: una reflexión (empírica) sobre sus confines. Anuario de Derecho Civil, 65 (3), 10011073.

De Amunátegui Rodríguez, C. (2008). Incapacitación y Mandato. Madrid: La Ley-Actualidad.

- (2018). La sustitución ejemplar como medida de protección de la persona. Madrid: Reus.

- (2019). El protagonismo de la persona con discapacidad en el diseño y gestión del sistema de apoyo. En S. de Salas Murillo y M. V. Mayor del Hoy (dirs.). Claves para la adaptación del ordenamiento jurídico privado a la Convención de $\mathrm{Na}$ ciones Unidas en materia de discapacidad (pp. 125). Valencia: Tirant lo Blanch.

De Salas Murillo, S. (2018). Significado jurídico del «apoyo en el ejercicio de la capacidad jurídica» de las personas con discapacidad: presente tras diez años de convención. Revista Doctrinal Aranzadi Civil-Mercantil, 5, 71-120.

Díaz Alabart, S. (1987). Comentario al art. 753. En M. Albaladejo García (dir.). Comentarios al Código Civil y Compilaciones Forales. Tomo X. (vol. 1). Madrid: EDERSA.

Espino Bernell, C. (2016). El testamento ológrafo. La importancia de la escritura y la firma del testador. El cotejo pericial de letras (la prueba caligráfica) [tesis doctoral]. Universidad de Córdoba. Disponible en: https://helvia.uco.es.

García Cantero, G. (2016). Comentario al art. 221. En A. Cañizares Laso, P. de Pablo Contreras, J. Orduña Moreno y R. Valpuesta Fernández (dirs.). Código civil comentado (vol. 1). Cizur Menor (Navarra): Thomson Reuters.

García Rubio, M. P. (2016a). Comentario al art. 752. En A. Cañizares Laso, P. de Pablo Contreras, J. Orduña Moreno y R. Valpuesta Fernández (dirs.). Código civil comentado (pp. 605-608) (2.a ed.). Cizur Menor (Navarra): Thomson Reuters.

- (2016b). Comentario al art. 753. En A. Cañizares Laso, P. de Pablo Contreras, J. Orduña Moreno y R. Valpuesta Fernández (dirs.). Código civil comentado (pp. 608-612) (2. a ed.). Cizur Menor (Navarra): Thomson Reuters.

Gómez Gálligo, F. J. (1992). Las prohibiciones de disponer. Madrid: Centro de Estudios Registrales.

Gómez Laplaza, M. C. y Díaz Alabart, S. (2014). La capacidad testamentaria de los incapacitados. En A. Domínguez Luelmo y M. P. García Rubio (dirs.) y M. Herrero Oviedo (coord.). Estudios de Derecho de Sucesiones. Liber Amicorum T. F. Torres García (pp. 529-546). Madrid: La Ley Wolters Kluwer.

Guilarte Martín-Calero, C. (2016). La capacidad para testar: una propuesta de reforma del artículo 665 del Código civil a la luz de la Convención internacional sobre los derechos de las personas con discapacidad. En VV. AA. y C. Guilarte Martín-Calero (coord.). Estudios y comentarios jurisprudenciales sobre discapacidad. Cizur Menor (Navarra): Thomson Reuters. 
Martínez de Aguirre Aldaz, C. (2018). Curso de Derecho civil. Tomo V. Derecho de Sucesiones. Madrid: Edisofer.

O’Callaghan Muñoz, X. (2000). Comentario al art. 752. I. En I. Sierra Gil de la Cuesta (dir.). Comentario del Código Civil. Tomo IV. Barcelona: Bosch.

Rodríguez Guitián, A. M. (2016). Comentario al artículo 665. En A. Cañizares Laso, P. de Pablo Contreras, F. J. Orduña Moreno y R. Valpuesta Fernández (dirs.). Código civil comentado (vol. 2). Cizur Menor (Navarra): Thomson Reuters.

Torres García, T. F. y García Rubio, M. ${ }^{a}$ P. (2014). La libertad de testar: el principio de igualdad, la dignidad de la persona y el libre desarrollo de la personalidad en el Derecho de sucesiones. Madrid: Fundación Coloquio Jurídico Europeo.

Trujillo Díez, I. (2016). Comentario al art. 753 (actualizado por J. J. Marín López). En R. Bercovitz Rodríguez-Cano (coord.). Comentarios al Código civil. Cizur Menor (Navarra): Aranzadi.

Vaquer Aloy, A. (2013). Libertad de disponer y testador vulnerable. En M. Cuena Casas, L. A. Anguita Villanueva y J. Ortega Doménech (coords.). Estudios de derecho civil en homenaje al profesor Joaquin José Rams Albesa (pp. 1801-1812). Madrid: Dykinson.

- (2015a) Libertad de testar y condiciones testamentarias. Indret: Revista para el Análisis del Derecho, 3, 1-40.

- (2015b). La protección del testador vulnerable. Anuario de Derecho Civil. Tomo LXVIII, 2, 327-368. Disponible en: https://doi.org/10.18272/iu.v14i16.731.

- (2018). Libertad de testar y libertad para testar. Santiago de Chile: Ediciones Jurídicas Olejni. 